\title{
Identification and Characterization of Sall1-Expressing Cells Present in the Adult Mouse Kidney
}

\author{
M. Joynal Abedin Naohiko Imai Mark E. Rosenberg Sandeep Gupta \\ Division of Renal Diseases and Hypertension, Stem Cell Institute and Department of Medicine, University of \\ Minnesota, Minneapolis, Minn., USA
}

\section{Key Words}

Stem cell $\cdot$ Kidney regeneration $\cdot$ Sall1 $\cdot$ Progenitor cells

\begin{abstract}
Background: Sall1 is a transcription factor that best identifies stem cells present in the mouse embryonic kidney. Mutations in Sall1 gene in mice can lead to dysgenesis of kidney, while in humans it results in the Townes-Brocks syndrome, which is associated with the kidney agenesis. Unlike the embryonic kidney, Sall1 expression in the adult kidney is largely unknown. We hypothesized that similar to the embryonic kidney, Sall1 expression can identify stem cells present in the adult kidney. Accordingly in this study, we identified Sall1-expressing cells in the adult mouse kidney, determined their role in kidney regeneration following ischemia-reperfusion injury (IRI), and sought the effect of age on Sall1 expression. Methods and Results: By immunofluorescence Sall1-expressing cells were identified in the proximal tubule at the cortico-medullary junction and constituted $0.5 \%$ of all tubular cells. Rare Sall1positive cells were also identified in the outer cortex and distal tubules. Sall1 expression was not seen in the glomerular, interstitial, or vascular compartments. Following IRI, $90 \%$ of
\end{abstract}

Sall1-expressing cells proliferated and 5\% of Sall1-positive cells showed asymmetrical cell division with one of the two adjacent Sall1-positive cells incorporating chlorodeoxyuridine (CldU). Following IRI, there was an increase in Sall1 expression at 4 and $12 \mathrm{~h}$, a decrease at 5 and 10 days, and baseline expression at day 30 by quantitative polymerase chain reaction (qRT-PCR) and Western blot analysis. There was no age-related change in Sall1 expression as determined by qRTPCR, Western blot analysis, and immunofluorescence. Conclusions: We conclude that Sall1-expressing cells are present in the adult mouse kidney, predominantly in the proximal tubules. Sall1-expressing cells proliferate following IRI and some of the Sall1-positive cells undergo asymmetrical cell division. Therefore, Sall1 is a promising marker for identification of stem cells present in the adult mouse kidney.

Copyright $\odot 2011$ S. Karger AG, Basel

\section{Introduction}

Stem cells are specialized cells that can self-renew and differentiate into mature cells. A fraction of the progeny of stem cells is a replica of the parent cell (self-renew),

\section{KARGER}

Fax +41613061234 E-Mail karger@karger.ch www.karger.com (c) 2011 S. Karger AG, Basel

$1660-2129 / 11 / 1194-0075 \$ 38.00 / 0$

Accessible online at:

www.karger.com/nee
Sandeep Gupta, MD

Division of Renal Diseases and Hypertension, Stem Cell Institute and

Department of Medicine, McGuire Translational Research Facility, Room 2-218

2001 6th Street S.E., Minneapolis, MN 55455 (USA)

E-Mail gupta024@umn.edu 
while others are destined to differentiate and form mature cells. Stem cells have been identified in several adult organs such as bone marrow, intestine, liver, brain, prostate, and skin, where they maintain the adult organ by replacing senescent cells and act as a cellular source during regeneration following injury [1]. Regarding the kidney, stem cells exist in the metanephric mesenchyme and give rise to all cell types present in the adult kidney, except those derived from the ureteric bud $[2,3]$. In organisms such as the skate and freshwater teleost, renal stem cells persist in the adult life and form new nephrons $[4,5]$. There is increasing debate whether stem cells exist in the adult mammalian kidney and participate in renal regeneration following injury $[6,7]$. Although great advances have been made in recent years, a major limitation in the field is the lack of definitive markers for identifying stem cells present in the adult mammalian kidney.

Sall1 is the mouse orthologue of Drosophila regionspecific homeotic gene spalt (sal). Spalt is an evolutionarily conserved gene family that plays important roles in organ development in Drosophila [8]. There are four known homologues of the Sall gene in mouse (Sall1-4) and human (SALL1-4). Sall1 protein is a $\mathrm{C} 2 \mathrm{H} 2$ zinc finger transcription factor with five zinc finger clusters distributed over the entire length of the protein [9]. Sall1 protein functions as a transcription repressor by associating with the histone deacetylase complex [10]. Sall1 is abundantly expressed in developing kidneys and plays a critical role in mammalian nephrogenesis [9]. Mice with homozygous deletion of Sall1 die in the perinatal period due to kidney agenesis. Homozygous deletion of Sall1 results in failure of ureteric bud growth and apoptosis of the metanephric mesenchyme [11]. In humans, mutations in the SALL1 gene results in Townes-Brocks syndrome, an autosomal dominant disease associated with kidney abnormalities [12]. Depending on the type of mutation, $20-60 \%$ of patients with Townes-Brocks syndrome have kidney agenesis, hypoplasia, dysplasia, or multicystic disease. In the developing metanephric mesenchyme, $20-30 \%$ of all cells express Sall1 [13]. Sall1 expression is seen in undifferentiated metanephric mesenchyme around the invading ureteric bud, and in the developing tubules and podocytes [11]. In the presence of Wnt4, clonally expanded Sall1-expressing cells differentiate into multiple mature kidney cells such as tubular cells and podocytes [13]. Recently, multipotent, clonogenic, long-term self-renewing progenitor cells have been isolated from the embryonic kidney [14]. Interestingly, these cells had sustained expression of Sall1 under culture conditions. By Northern blot analysis, the highest level of Sall1 expression of all adult tissues is seen in the kidney [15].

The expression of Sall1 by embryonic kidney stem cells, its important role in nephrogenesis, and expression in the adult kidney, makes Sall1 a potential candidate marker of stem cells present in the adult kidney. Accordingly, the goal of this study was to determine the expression pattern of Sall1 in the adult mouse kidney, their role in kidney regeneration, and sought age-related alterations in the expression in adult kidneys.

\section{Materials and Methods}

\section{Materials}

Mice. C57BL/6 mice, 7 weeks to 10 months old, were used in the experiments. All mice were purchased from Harlan Laboratories (Indianapolis, Ind., USA) and housed in the Research Animal Resource facility at the University of Minnesota. All animal experiments were performed under the guidelines and protocols approved by the Institutional Animals Care and Use Committee at the University of Minnesota.

Chemicals/Reagents. Chlorodeoxyuridine (CldU) was purchased from Sigma-Aldrich (St. Louis, Mo., USA). Sybr Green ER qPCR SuperMix for ABI Prism and Tyramide Signal Amplification (TSA) Kit were purchased from Invitrogen (Carlsbad, Calif., USA). Sytox Green was purchased from Molecular Probes (Eugene, Oreg., USA) and the antigen retrieval solution (BD Retrievagen $\mathrm{B}, \mathrm{pH}$ 9.5) was from BD Bioscience Pharmingen (San Diego, Calif., USA). Pierce SuperSignal West Femto Kit (Thermo Scientific, Ill., USA) was used for the detection of Western blot (WB) signal.

Antibodies and Lectins. Mouse monoclonal anti-Salll antibody (PP-K9814-002) was purchased from R\&D Systems (Minneapolis, Minn., USA). The goat polyclonal anti-Sall1 (N-17) antibody (sc-46037) and blocking peptide (ZK9814H) were purchased from Santa Cruz Biotechnology (Santa Cruz, Calif., USA). The rat monoclonal anti-BrdU antibody (BU1/75 (ICR1) that recognizes CldU was purchased from Novus Biological (Littleton, Colo., USA). Mouse anti- $\beta$-actin antibody was obtained from Calbiochem (Los Angeles, Calif., USA). FITC-conjugated Pheseolus vulgaris erythroagglutinin (PHA-E, \#FL-1121) and peanut agglutinin (PNA, \#FL-1071) were purchased from Vector Laboratories (Burlingame, Calif., USA). Fluoro-gel mounting media was purchased from Electron Microscopy Sciences (Hatfield, Pa., USA).

\section{Methods}

Acute Kidney Injury and Administration of CldU. We performed survival surgeries in mice under isoflurane anesthesia and sterile surgical conditions. We induced acute ischemia-reperfusion injury (IRI) by clamping of bilateral renal arteries for 30 min at $37^{\circ} \mathrm{C}$. We subcutaneously administered the first dose of CldU (30 mg/kg) $48 \mathrm{~h}$ following IRI. The second dose of CldU was administered $4 \mathrm{~h}$ following the first dose and kidneys were har- 
vested between 68 and $72 \mathrm{~h}$ following IRI. The control mice received the vehicle without CldU.

Immunohistochemistry. 4\% paraformaldehyde-fixed, paraffin-embedded, 5- $\mu \mathrm{m}$ mouse kidney sections were used for immunofluorescence. Sall1 epitope was retrieved using Retrievagen $B$ solution as per manufacturer's protocol. The antigen-retrieved sections were subsequently incubated overnight at $4^{\circ} \mathrm{C}$ with $1: 10$ dilution of the mouse monoclonal anti-Sall1 antibody. The primary antibody was detected using 1:100 dilution of HRP-conjugated anti-mouse IgG secondary antibody. The HRP signal was amplified using Tyramide Signal Amplification Kit as per manufacturer's protocol. To identify proximal and distal tubules, we incubated the kidney sections for $1 \mathrm{~h}$ at $37^{\circ} \mathrm{C}$ with $20 \mu \mathrm{g} / \mathrm{ml}$ solution of FITC-labeled PHA-E and PNA respectively. Subsequently, nuclei were counterstained with $1 \mu \mathrm{M}$ Sytox Green for $10 \mathrm{~min}$ at room temperature. The stained sections were mounted with Fluoro-gel and coverslipped.

Quantification of Sall1-Positive Cells. We counted Sall1-positive cells under $40 \times$ magnification in the outer cortex, corticomedullary junction (CMJ), medulla, and papilla. Sall1-positive cells in proximal and distal tubules were counted separately. At least 10 fields were counted at each location. Sall1-positive cells were represented as the percentage of total number of nuclei counted.

$q R T-P C R$. Total RNA was isolated and purified from kidney tissue. $2 \mu \mathrm{g}$ of RNA was reverse-transcribed to cDNA and $20 \mathrm{ng}$ of cDNA was used as the template for Sall1 and $\beta$-actin (housekeeping gene) qPCR. The primers for Sall1 and $\beta$-actin, and the PCR conditions were as follows: Sall1: forward 5' CAATCTGAAGGTCCACATGGGCAC 3' and reverse 5' TGCCTCCTAGAAATGTCATGGG 3'; $\beta$-actin: forward 5' AAGAGCTATGAGCTGCCTGA $3^{\prime}$ and reverse 5' TACGGATGTCAACGTCACAC $3^{\prime}$; PCR conditions were $95^{\circ} \mathrm{C}$ for $10 \mathrm{~s}$, followed by 40 cycles at $95^{\circ} \mathrm{C}$ for $15 \mathrm{~s}, 60^{\circ} \mathrm{C}$ for $1 \mathrm{~min}$ and $72^{\circ} \mathrm{C}$ for $20 \mathrm{~s}$.

WB Analysis. Proteins were extracted from the non-ischemic and ischemic mouse kidney with mammalian tissue extraction/ lysis reagent supplemented with protease inhibitors. Lysates (50-75 $\mu \mathrm{g}$ of total protein) were electrophoretically separated by $10 \%$ sodium dodecyl sulfate-polyacrylamide gel electrophoresis and transferred to the nitrocellulose membrane. Membrane blocking, washing, primary and secondary antibody incubations, and chemiluminescence reactions were carried out according to Pierce SuperSignal West Femto Kit protocol. Antibody dilutions were carried out as per data sheet provided by the manufacturer. Blots were stripped for reprobing by washing with TBS-T buffer ( $\mathrm{pH}$ 2.5-3.0) at room temperature for $30 \mathrm{~min}$. The specificity of the Sall1 band was determined by using a Sall1 antibody-blocking peptide according to the manufacturer's protocol.

\section{Results}

\section{Localization of Sall1-Expressing Cells}

We have performed all experiments in triplicate and shown only the representative images in this work. We first investigated Sall1 expression in the adult mouse kidney by standard immunofluorescence methods. We identified Sall1 staining (fig. la-f, red staining and arrow) in $0.5 \%$ of nuclei of tubular cells at the CMJ (fig. 1b) in the non-ischemic kidney. We did not see Sall1 staining in the glomerular, vascular, or interstitial compartments. There were only rare Sall1-positive cells in the outer cortex (fig. 1a), and none in the papilla (fig. 1c). The majority of Sall1-expressing cells were present in the PHA-E-positive proximal tubules (fig. 1a, d, green staining, yellow arrow), and rarely in the PNA-positive distal tubules (fig. 1e, green staining, yellow arrow). We confirmed nuclear localization of Sall1 expression by co-staining nuclei with the Sytox Green (fig. 1f, green staining and arrow). The Sall1-positive cells in the outer cortex and distal tubules were too infrequent for quantification.

\section{Proliferation of Sall1-Expressing Cells during Kidney Regeneration}

Following IRI, 90\% of Sall1-positive cells incorporated CldU, suggesting their cell cycle progression. 5\% of Sall1positive cells showed asymmetrical cell division with one of the two adjacent Sall1-positive cells incorporating CldU. As shown in figure 2 (yellow arrowhead), unlike non-ischemic kidney, in the ischemic kidney at several places there were two adjacent cells that were Sall1-positive. Furthermore, there were chains of CldU-positive cells immediately adjacent to the Sall1-positive cells in the ischemic kidney, suggesting their derivation from the Sall1-positive cell. We acknowledge that tubule is a threedimensional structure, and we could have missed a real sibling of the daughter cell. However, we did not see two adjacent Sall1-positive cells in the non-ischemic kidney. Despite cell division of Sall1-positive cells, there was no change in the percentage of Sall1-positive cells present in the kidney following IRI. This was likely because of the presence of Sall1-positive cells in a very low numbers in the kidney. None of the Sall1-positive cells present in the distal tubule proliferated following IRI.

\section{Western Blot Analysis of Sall1 Expression following Acute Kidney Injury}

Protein isolated from the non-ischemic and ischemic kidney (68-72 $\mathrm{h}$ following $30 \mathrm{~min}$ of bilateral renal artery clamping) was run on a gel and probed with the anti-Sall1 antibody alone (fig. 3, left two lanes), or following blocking of the primary antibody with the Sall1-blocking peptide (fig. 3, right two lanes). Absence of bands in the right two lanes following blocking supports specificity of the Sall1 antibody. We used $\beta$-actin as the loading control (fig. 3, bottom panel). The mass of Sall1 and $\beta$-actin proteins is 

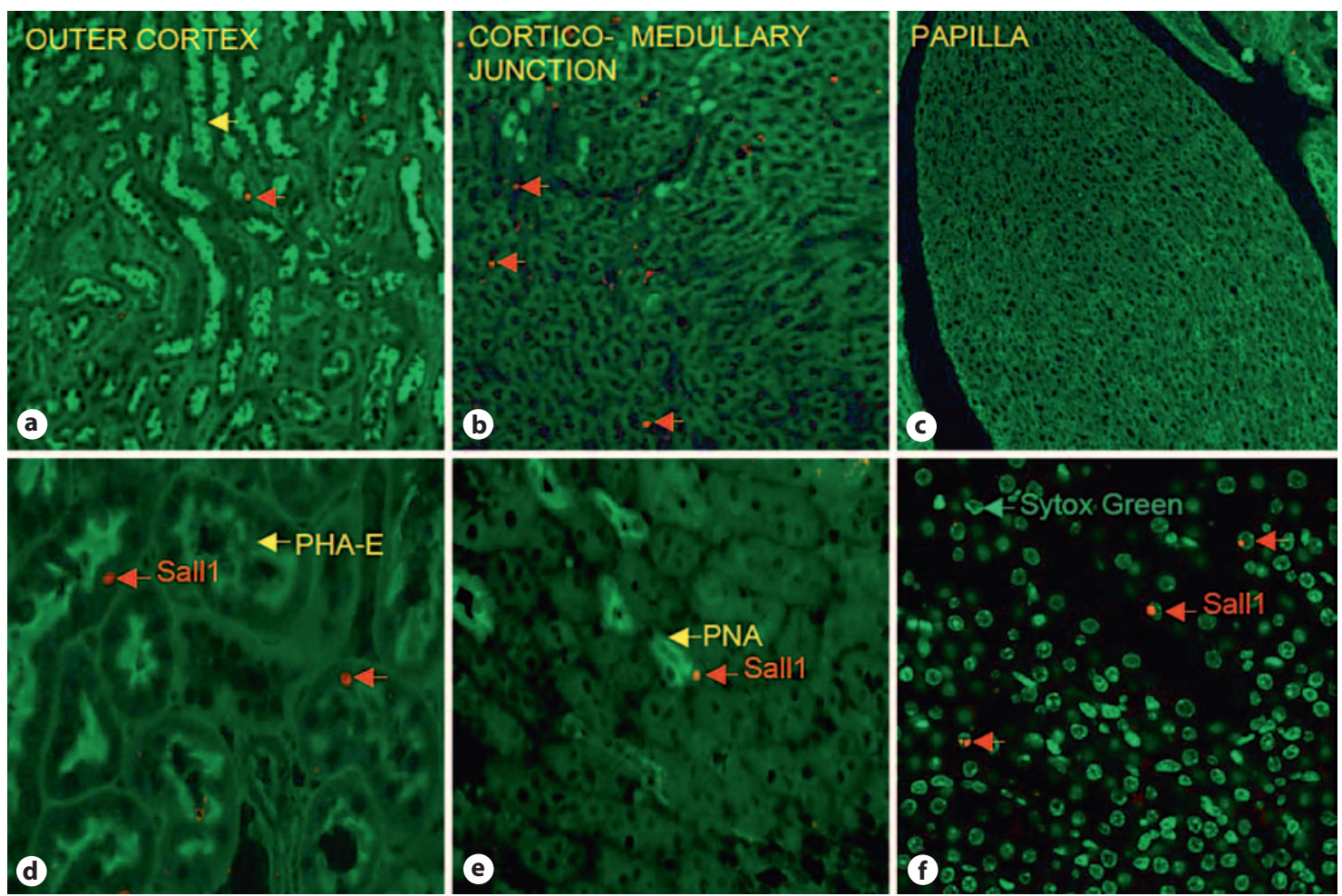

Fig. 1. Localization of Sall1-expressing cells in the adult mouse kidney: Sall1 (red staining and arrow) expression was seen in $0.5 \%$ of tubular cells in non-ischemic adult mouse kidney. No Sall1 staining was seen in the glomerular, vascular, or interstitial compartments. Sall1-expressing cells were most abundant at the CMJ $(\mathbf{b}, \times 20)$. There were rare Sall1-positive cells in the outer cortex (a, $\times 20)$, and none in the papilla $(\mathbf{c}, \times 20)$. Sall1-expressing cells were predominantly present in the PHA-E-positive proximal tubule (a, $\times 20$ and $\mathbf{d}, \times 40$; yellow arrow), and rarely in the PNApositive distal tubules (e, $\times 40$; yellow arrow). We confirmed nuclear localization of Sall1 expression by co-staining with Sytox Green $(\mathbf{f}, \times 40)$.
140 and $42 \mathrm{kDa}$, respectively. We detected less Sall1 expression in the adult kidneys 3 days following ischemic injury as compared to the non-ischemic controls.

\section{qRT-PCR Analysis of Sall1 Expression following Acute} Kidney Injury

We quantified Sall1 expression in the kidney by qRTPCR (fig. 4). There was an increase in Sall1 expression at 4 and $12 \mathrm{~h}$ followed by a decrease on days 5 and 10 following IRI. The Sall1 expression returned to baseline by day 30 following injury. The qRT-PCR results from kidneys harvested 68-72 h were similar to those harvested 5 days following IRI. We did not include the data from kidneys harvested $68-72 \mathrm{~h}$ following IRI in figure 4 as samples were not collected simultaneously and therefore were not true biological replicates. The reduction in Sall1 gene expression following IRI is consistent with the reduction in protein expression seen in $\mathrm{WB}$ analysis (fig. 3).

\section{Lack of Alteration in Sall1 Expression with Aging}

Stem cell numbers have been shown to decline with aging in several adult organs. We quantified age-associated change in Sall1 expression in kidneys of 4-week-, 10week-, 6-month- and 10-month-old mice by WB analysis, using $\beta$-actin as the loading control (fig. 5). We confirmed results of WB analysis by qRT-PCR and immunofluorescence (data not shown). We did not see any change in the quantity or distribution of Sall1 expression with aging. Of note, we used polyclonal anti-Sall1 antibody for experiments in figure 3 and monoclonal anti-Sall1 antibody for experiments in figure 5 . The detection of multiple protein bands by the polyclonal antibody is likely resulting from binding with either non-specific proteins or degradation products of Sall1 protein. The use of polyclonal antibody was essential over more specific monoclonal antibody for experiments in figure 3 because of lack of availability of a blocking peptide for the monoclonal antibody. 


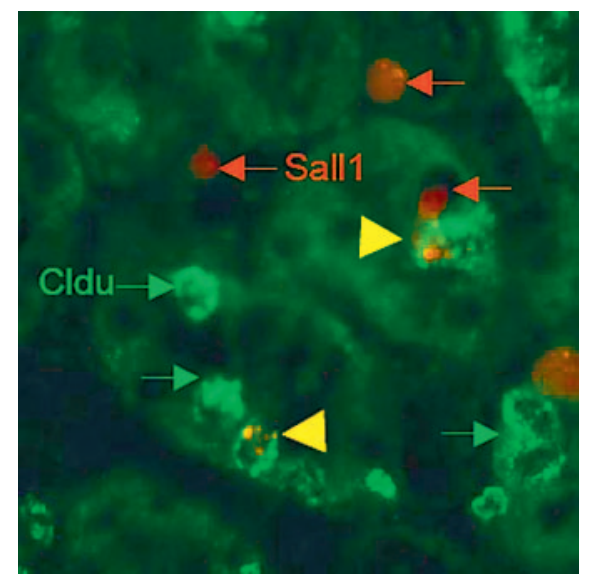

Fig. 2. Proliferation and asymmetric cell division of Sall1-expressing cells following acute kidney injury $(\times 100)$ : following IRI, CldU was incorporated into the replicating DNA during cell division. Sall1 (stained red; red arrow) and CldU (stained green; green arrow) expressing cells were detected by immunofluorescence. Cells that were double positive for CldU and Salli are marked by yellow arrowhead. Interestingly, there were chains of CldU-positive cells immediately adjacent to Sall-positive cells (right lower corner), suggesting their derivation from Sall1-positive cell.

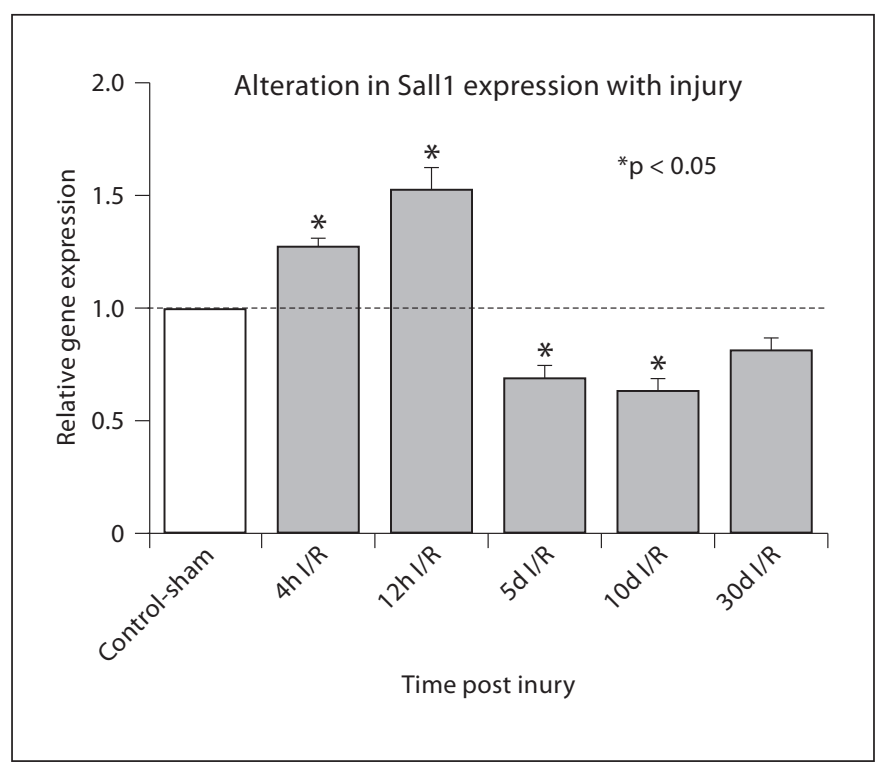

Fig. 4. qRT-PCR analysis of Sall1 expression following acute kidney injury: a transient increase in Sall1 expression was seen following injury as compared to baseline at $4(\mathrm{p}=0.04)$ and $12 \mathrm{~h}$ $(\mathrm{p}=0.04)$. Expression, decreased at day $5(\mathrm{p}=0.04)$ and $10(\mathrm{p}=$ $0.03)$ before returning to baseline values by day $30(p=0.10)$.

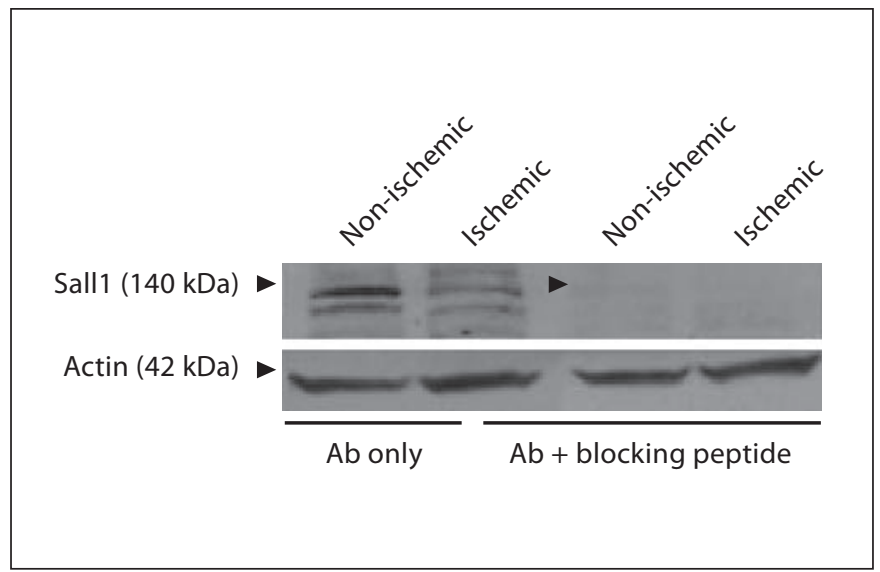

Fig. 3. WB analysis of Sall1 expression in adult mouse kidney: protein isolated from non-ischemic and ischemic kidney $(72 \mathrm{~h}$ following $30 \mathrm{~min}$ of bilateral renal artery clamping) was run on a gel and probed with anti-Sall1 antibody alone (left two lanes), or following blocking of the antibody with the Sall1-blocking peptide (right two lanes). Absence of bands in right two lanes following blocking with the peptide supports specificity of the anti-Sall1 antibody. Sall1 and $\beta$ actin are respectively $140 \mathrm{kDa}$ (arrowhead) and $42 \mathrm{kDa}$ in mass. We detected less Sall1 protein in the ischemic kidney as compared to the non-ischemic control.

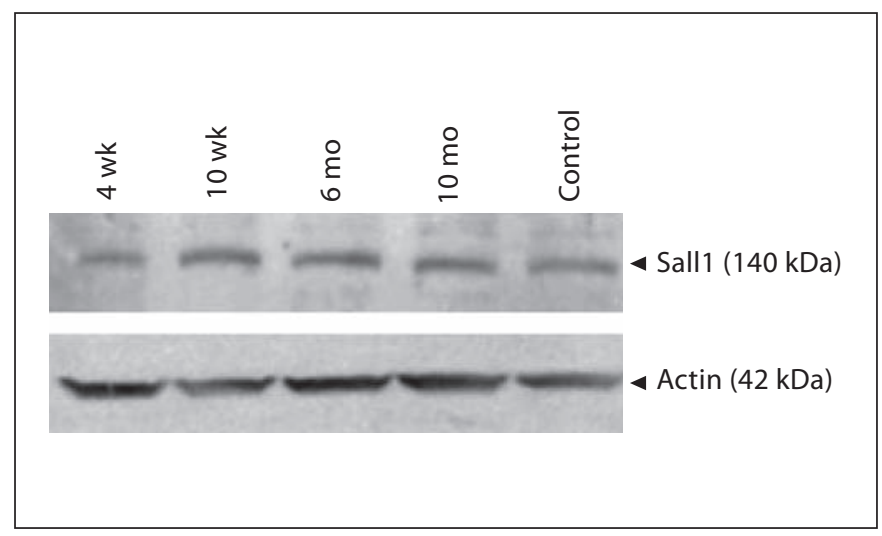

Fig. 5. Sall1 expression and aging: WB of kidneys harvested from 4-week-, 10-week-, 6-month- and 10-month-old mice probed with anti-Sall1 antibody. There was no significant difference in Sall1 expression among mice of different ages. 


\section{Discussion}

This is the first study to identify and characterize tissue distribution of Sall1-expressing cells in the adult mouse kidney. We demonstrated proliferation of Sall1-expressing cells following acute kidney injury. Existence of stem cells in the adult kidney has important implications for understanding the cellular source of normal cell turnover and kidney regeneration following injury. Investigators have identified potential stem cells in the adult mammalian kidney using various methods [16-20]. Oliver et al. [19] identified slow cycling cells in the papilla of adult rodent kidneys, based on retention of thymidine analogue BrdU. Using a similar approach, Maeshima et al. [18] identified BrdU-retaining cells in the rat renal tubules at the $\mathrm{CMJ}$ that could differentiate into renal proximal tubular and collecting duct cells following transplantation into embryonic kidneys. Kitamura et al. [17] characterized a distinct population of renal progenitor cells in the S3 segment of the adult rat nephrons. These cells could self-renew and expressed markers of developing kidney, such as Pax-2, Wnt4, and Wnt1. Stem cells frequently extrude Hoechst dye and are called the 'side population cells' because of their unique location in the scatter plot during fluorescence assisted cell sorting (FACS). Such side population cells with multipotent differentiation potential have been identified in the mouse embryonic and adult kidneys [21]. Gupta et al. [20] identified multipotent renal progenitor cells expressing embryonic stem cell markers Oct-4 and Pax-2 in the adult rat kidney at the CMJ.

The discrepancies in the location and characteristics of stem cells identified in these studies likely result from differences in the identification method, species, and age of the animals studied, and culture conditions used for isolation. Although several investigators have identified potential kidney stem cell markers, none of the current markers are unique or definitive, necessitating continued search for an ideal marker. Identification of renal stem cell marker will significantly facilitate development of stem cell-based therapies for kidney regeneration. It has been well known that active proliferation occurs at the $\mathrm{CMJ}$ following ischemic kidney injury. Since the proliferating cell nuclear antigen, a marker of cell proliferation, is detected primarily in the S3 segment of the proximal tubule following ischemic kidney injury, it has been speculated that the S3 segment is a potential stem cell niche in the adult kidney $[22,23]$. In this study, we tested our hypothesis that Sall1, one of the best-characterized markers of embryonic kidney stem cells, can also identify stem cells present in the adult kidney.
We first localized Sall1-expressing cells in the adult mouse kidney by immunofluorescence. No Sall1 staining was seen in the glomerular, vascular, or interstitial compartments. Sall1-expressing cells were found exclusively in the tubular compartment most abundantly at the CMJ, followed by the outer cortex, with none present in the papilla. CMJ is the site of maximum hypoxic injury due to the delicate balance that exists here between the demand and supply of energy in the metabolically active segments of the kidney, such as S3 segment of the proximal tubules and the thick ascending limb of loop of Henle. Presence of Sall1-expressing cells at the site of maximum demand during kidney regeneration makes biological sense. Our result supports previous studies demonstrating presence of cells expressing stem cell markers such as Oct4 and CD133 at the CMJ and cortex, respectively $[16,20,24]$.

To further characterize the role of Sall1-expressing cells in kidney regeneration, we examined proliferation of these cells following ischemic kidney injury. Acute ischemic kidney injury is frequently seen in the modernday clinical practice, such as following surgery, trauma, and transplantation [25]. Presently, regeneration following acute kidney injury is believed to occur predominantly by proliferation of surviving tubular epithelial cells. We hypothesized that Sall1-expressing cells are adult kidney stem cells that contribute to the regenerative response following injury. Interestingly, frequently only one of the two adjacent CldU-positive cells was double positive for Sall1 suggesting asymmetrical cell division of Sall1-expressing cells, a finding supporting their stemness. We hypothesize that increased Sall1 expression immediately following kidney injury, followed by decreased expression at 10 days, and restoration of Sall1 expression by day 30 is because of proliferation, differentiation, and restoration of Sall1-expressing cells following injury. Our data from this study do not contradict the more conventional view that differentiated cells are the predominant source for replacing injured renal cells $[22,26]$. The two potential cellular sources of kidney regeneration are not mutually exclusive and could be requirement specific.

With aging, the ability of organisms to maintain cellular homeostasis during normal cell turnover and regeneration declines, resulting in structural and functional compromise of various organs. The number and function of stem cells have been shown to decline with aging in various organs, such as, skin, gut, muscle, and central nervous system [27-29]. Both human and animal data demonstrate age-associated decline in kidney function [30]. Stem cells have preserved telomere length and with decline in stem 
cell number, one expects reduction in the average telomere length in an organ. Melk et al. [31, 32] have demonstrated a decline in the telomere length in human kidneys with aging. We hypothesized that age-associated decline in kidney function results from loss of kidney stem cells. To test our hypothesis, we examined the age-associated alteration in Sall1 expression. Our result did not show decline in Sall1 expression in mice up to the age of 10 months by WB analysis, qRT-PCR, or immunofluorescence.

\section{Conclusion}

This is the first study to demonstrate localization of Sall1-expressing cells in the adult mouse kidney. Also, Sall1 being one of the best-characterized embryonic kidney stem cell markers, our findings of asymmetrical cell division of Sall1-expressing cells during kidney regeneration and transient decrease in Sall1 expression following injury, makes Sall1 a promising marker of adult kidney stem cells. Our initial findings will form the basis for future studies validating stemness of Sall1-expressing cells by more definitive methods, such as in vivo cell lineage tracking using a transgenic approach.

\section{Disclosure Statement}

The authors have no conflicts of interest to disclose.

\section{References}

$\rightarrow$ Eckfeldt CE, Mendenhall EM, Verfaillie CM: The molecular repertoire of the 'almighty' stem cell. Nat Rev Mol Cell Biol 2005;6:726737.

2 Oliver JA, Barasch J, Yang J, Herzlinger D, Al-Awqati Q: Metanephric mesenchyme contains embryonic renal stem cells. Am J Physiol Renal Physiol 2002;283:F799-F809.

-3 Herzlinger D, Koseki C, Mikawa T, al-Awqati Q: Metanephric mesenchyme contains multipotent stem cells whose fate is restricted after induction. Development 1992;114:565-572.

4 Drummond I: The skate weighs in on kidney regeneration. J Am Soc Nephrol 2003; 14: 1704-1705.

-5 Elger M, Hentschel H, Litteral J, Wellner M, Kirsch T, Luft FC, Haller H: Nephrogenesis is induced by partial nephrectomy in the elasmobranch Leucoraja erinacea. J Am Soc Nephrol 2003;14:1506-1518.

-6 Gupta S, Rosenberg ME: Do stem cells exist in the adult kidney? Am J Nephrol 2008;28: 607-613.

7 Rosenberg ME, Gupta S: Stem cells and the kidney: where do we go from here? J Am Soc Nephrol 2007;18:3018-3020.

$\checkmark 8$ Sweetman D, Munsterberg A: The vertebrate spalt genes in development and disease. Dev Biol 2006;293:285-293.

-9 Yamashita K, Sato A, Asashima M, Wang PC, Nishinakamura R: Mouse homolog of Sall1, a causative gene for Townes-Brocks syndrome, binds to $\mathrm{A} / \mathrm{T}$-rich sequences in pericentric heterochromatin via its C-terminal zinc finger domains. Genes Cells 2007; $12: 171-182$
10 Lauberth SM, Rauchman M: A conserved 12-amino-acid motif in Sall1 recruits the nucleosome remodeling and deacetylase co-repressor complex. J Biol Chem 2006;281: 23922-23931.

11 Nishinakamura R, Matsumoto Y, Nakao K, Nakamura K, Sato A, Copeland NG, Gilbert DJ, Jenkins NA, Scully S, Lacey DL, Katsuki M, Asashima M, Yokota T: Murine homolog of Sall1 is essential for ureteric bud invasion in kidney development. Development 2001; 128:3105-3115.

12 Kohlhase J, Wischermann A, Reichenbach $\mathrm{H}$, Froster U, Engel W: Mutations in the Sall putative transcription factor gene cause Townes-Brocks syndrome. Nat Genet 1998; 18:81-83.

13 Nishinakamura R, Osafune K: Essential roles of Sall family genes in kidney development. J Physiol Sci 2006;56:131-136.

14 Lusis M, Li J, Ineson J, Christensen ME, Rice A, Little MH: Isolation of clonogenic, longterm self-renewing embryonic renal stem cells. Stem Cell Res 2010;5:23-39.

15 Kohlhase J, Schuh R, Dowe G, Kuhnlein RP, Jackle H, Schroeder B, Schulz-Schaeffer W, Kretzschmar HA, Kohler A, Muller U, RaabVetter M, Burkhardt E, Engel W, Stick R: Isolation, characterization, and organ-specific expression of two novel human zinc finger genes related to the Drosophila gene spalt. Genomics 1996;38:291-298.

16 Bussolati B, Bruno S, Grange C, Buttiglieri S, Deregibus MC, Cantino D, Camussi G: Isolation of renal progenitor cells from adult human kidney. Am J Pathol 2005;166:545-555.
17 Kitamura S, Yamasaki Y, Kinomura M, Sugaya T, Sugiyama H, Maeshima Y, Makino $\mathrm{H}$ : Establishment and characterization of renal progenitor-like cells from S3 segment of nephron in rat adult kidney. FASEB J 2005; 19:1789-1797.

18 Maeshima A, Yamashita S, Nojima Y: Identification of renal progenitor-like tubular cells that participate in the regeneration processes of the kidney. J Am Soc Nephrol 2003; 14: 3138-3146.

19 Oliver JA, Maarouf O, Cheema FH, Martens $\mathrm{TP}, \mathrm{Al}$-Awqati Q: The renal papilla is a niche for adult kidney stem cells. J Clin Invest 2004;114:795-804.

20 Gupta S, Verfaillie C, Chmielewski D, Kren S, Eidman K, Connaire J, Heremans Y, Lund T, Blackstad M, Jiang Y, Luttun A, Rosenberg ME: Isolation and characterization of kidney-derived stem cells. J Am Soc Nephrol 2006; 17:3028-3040.

21 Challen GA, Bertoncello I, Deane JA, Ricardo SD, Little MH: Kidney side population reveals multilineage potential and renal functional capacity but also cellular heterogeneity. J Am Soc Nephrol 2006;17:1896-1912.

22 Witzgall R, Brown D, Schwarz C, Bonventre JV: Localization of proliferating cell nuclear antigen, vimentin, $\mathrm{c}-\mathrm{fos}$, and clusterin in the postischemic kidney. Evidence for a heterogenous genetic response among nephron segments, and a large pool of mitotically active and dedifferentiated cells. J Clin Invest 1994; 93:2175-2188.

23 Park SK, Kang MJ, Kim W, Koh GY: Renal tubule regeneration after ischemic injury is coupled to the up-regulation and activation of cyclins and cyclin-dependent kinases. Kidney Int 1997;52:706-714. 
-24 Sagrinati C, Netti GS, Mazzinghi B, Lazzeri E, Liotta F, Frosali F, Ronconi E, Meini C, Gacci M, Squecco R, Carini M, Gesualdo L, Francini F, Maggi E, Annunziato F, Lasagni L, Serio M, Romagnani S, Romagnani P: Isolation and characterization of multipotent progenitor cells from the Bowman's capsule of adult human kidneys. J Am Soc Nephrol 2006;17:2443-2456.

-25 Nash K, Hafeez A, Hou S: Hospital-acquired renal insufficiency. Am J Kidney Dis 2002; 39:930-936.
26 Humphreys BD, Valerius MT, Kobayashi A, Mugford JW, Soeung S, Duffield JS, McMahon AP, Bonventre JV: Intrinsic epithelial cells repair the kidney after injury. Cell Stem Cell 2008;2:284-291.

27 Rando TA: Stem cells, ageing and the quest for immortality. Nature 2006;441:1080-1086.

28 Kirkwood TB: Intrinsic ageing of gut epithelial stem cells. Mech Ageing Dev 2004;125: 911-915.

29 Conboy IM, Rando TA: Aging, stem cells and tissue regeneration: lessons from muscle. Cell Cycle 2005;4:407-410.
0 Clark B: Biology of renal aging in humans. Adv Ren Replace Ther 2000;7:11-21.

31 Melk A, Ramassar V, Helms LM, Moore R, Rayner D, Solez K, Halloran PF: Telomere shortening in kidneys with age. J Am Soc Nephrol 2000;11:444-453.

32 Westhoff JH, Schildhorn C, Jacobi C, Homme M, Hartner A, Braun H, Kryzer C, Wang C, von Zglinicki T, Kranzlin B, Gretz N, Melk A: Telomere shortening reduces regenerative capacity after acute kidney injury. J Am Soc Nephrol 2010;21:327-336. 